\title{
Chemerin level in a sample of Egyptian females with PCOS and its relation to insulin resistance
}

\author{
Mohamed Reda Halawa, Rania Said Abd El Baky, Yara Mohamed Eid, Merhan Samy Nasr,
} Bahaa Mahmoud Taha and Laila Mahmoud Ali Hendawy*

\begin{abstract}
Background: Chemerin a novel adipokine is linked to insulin resistance and adiposity which are major characteristics of polycystic ovary syndrome (PCOS).

Results: Chemerin level was found to be significantly higher in PCOS group than in control group $(94.99 \pm 12.52 \mathrm{ng} / \mathrm{dl}$ vs $73.41 \pm 6.95 \mathrm{ng} / \mathrm{dl})(P<0.001)$ being the highest in obese PCO group, also chemerin positively correlated with BMl, fasting insulin, and HOMA-IR $(P<0.001)$, Multivariate linear regression analysis for factors affecting chemerin level in both PCO groups showed that the most important factor was fasting insulin $(P=0.042)$.

Conclusion: Chemerin correlates with insulin resistance and may be involved in the pathogenesis of insulin resistance in PCOS patients.
\end{abstract}

Keywords: Insulin resistance, Chemerin, PCOS

\section{Background}

Several studies have pinpointed insulin resistance (IR) as the fundamental link associating PCOS and obesity [1] though IR may be present in PCOS independently of obesity [2]. IR seems to be an essential pathophysiologic mechanism in the development of all metabolic aspects of PCOS [3].

Chemerin is an adipokine that can regulate glucose uptake and stimulate lipolysis via phosphorylation of some intermediates in human adipocytes which are involved in mediating lipolysis and insulin signaling pathway [4]. So, we aim to evaluate the level of serum chemerin in a sample of Egyptian females with polycystic ovary syndrome and its relation to insulin resistance in those patients.

\footnotetext{
* Correspondence: Dr_Ima@yahoo.com

Ain Shams University Hospital, Cairo, Egypt
}

\section{Methods}

Our case control study was conducted on 90 females with mean age $28.93 \pm 5.11$ years from June 2017 to June 2018 in Cairo, Egypt. Our study was accepted by our local Research Ethics Committee (REC) FWA 000017858 and a written consent was taken from all subjects to be included in our study. Those females were divided into two groups. Group 1 included 45 females with PCOS attending our endocrinology and gynecology outpatient clinics diagnosed according to Rotterdam criteria [5]. This group was further subdivided according to BMI into, group 1A) 27 obese PCO and group 1B) 18 lean PCO.

Group 2 included 45 normal healthy females as a control group which was further subdivided according to BMI into, group 2A) 25 obese women and group 2B) 20 lean women.

The Rotterdam criteria were used for the diagnosis of PCOS women with at least two of the following were included in the PCOS group: oligo/anovulation; clinically apparent or biochemically verified hyperandrogenism; 
Table 1 Descriptive data of the studied groups as regards all studied parameters

\begin{tabular}{|c|c|c|c|c|c|}
\hline Studied parameters & & $\begin{array}{l}\text { Obese PCO } \\
\text { No. }=27\end{array}$ & $\begin{array}{l}\text { Lean PCO } \\
\text { No. }=18\end{array}$ & $\begin{array}{l}\text { Obese control } \\
\text { No. }=25\end{array}$ & $\begin{array}{l}\text { Lean contro } \\
\text { No. }=20\end{array}$ \\
\hline Age (years) & Mean \pm SD & $26.44 \pm 2.62$ & $26.61 \pm 3.11$ & $27.76 \pm 3.84$ & $27.80 \pm 4.07$ \\
\hline BMI $\left(\mathrm{kg} / \mathrm{m}^{2}\right)$ & Mean \pm SD & $33.25 \pm 2.14$ & $23.36 \pm 1.08$ & $33.20 \pm 2.15$ & $23.60 \pm 0.90$ \\
\hline $\begin{array}{l}\text { Systolic blood } \\
\text { pressure }(\mathrm{mm} / \mathrm{Hg})\end{array}$ & Mean \pm SD & $110.93 \pm 7.47$ & $106.11 \pm 8.14$ & $108.20 \pm 6.75$ & $109.25 \pm 7.66$ \\
\hline $\begin{array}{l}\text { Diastolic blood } \\
\text { pressure (mm/Hg) }\end{array}$ & Mean \pm SD & $68.89 \pm 7.38$ & $69.17 \pm 6.70$ & $68.20 \pm 7.05$ & $67.75 \pm 5.73$ \\
\hline Fasting sugar mg/dl & Mean \pm SD & $84.96 \pm 4.89$ & $84.78 \pm 5.21$ & $82.64 \pm 4.91$ & $81.55 \pm 3.87$ \\
\hline Fasting insulin $\mu \mathrm{IU} / \mathrm{mL}$ & Mean \pm SD & $19.50 \pm 4.21$ & $13.34 \pm 1.45$ & $12.15 \pm 2.16$ & $8.81 \pm 2.33$ \\
\hline HOMA-IR & Mean \pm SD & $4.12 \pm 1.03$ & $2.79 \pm 0.37$ & $2.47 \pm 0.44$ & $1.77 \pm 0.47$ \\
\hline Chemerin (ng/dl) & Mean \pm SD & $99.65 \pm 13.72$ & $87.99 \pm 5.64$ & $76.82 \pm 2.39$ & $69.16 \pm 8.40$ \\
\hline
\end{tabular}

typical ovarian morphology on pelvic ultrasonography [5].

All subjects included in this study were subjected to full medical history taking including age, smoking history, menstrual history, thorough physical examination including blood pressure, and anthropometric measurements including body mass index and hirsutism.

\section{Exclusion criteria}

Subjects with diabetes mellitus, hypertension; other endocrine pathologies leading to hyperandrogenism were excluded from our study. None of the patients had used oral contraceptives, glucocorticoids, ovulation induction agents, anti-obesity drugs, or any other steroid containing drug for the last 2 months prior to the study.

Laboratory investigations included the following:

Fasting blood glucose in $\mathrm{mg} / \mathrm{dl}$ by automated Beckman Coulter by glucose oxidase method, fasting insulin in $\mu \mathrm{IU} / \mathrm{ml}$ by ELISA, and serum chemerin by ELISA. HOMA IR was calculated according to the Mathews et al. (1985) equation: Fasting plasma glucose $(\mathrm{mg} / \mathrm{dl}) \times$ Fasting serum insulin $\mu \mathrm{IU} / \mathrm{ml} / 405$.

\section{Methods}

After $8 \mathrm{~h}$ of overnight fasting, $5 \mathrm{ml}$ of venous blood was collected by using sterile plastic syringe, for measurement of fasting blood sugar, fasting serum insulin, and serum chemerin. Serum was separated by centrifugation and frozen at -20 until assayed.

\section{Statistical analysis}

Data were collected, revised, coded, and entered to the Statistical Package for Social Science (IBM SPSS) version 23. The quantitative data were presented as mean, standard deviations and ranges when their distribution found parametric. Also qualitative variables were presented as number and percentages. The comparison between groups regarding qualitative data was done by using chisquare test. The comparison between two independent groups with quantitative data and parametric distribution were done by using independent $t$ test. The comparison between more than two independent groups with quantitative data and parametric distribution were done by using one-way ANOVA test followed by post hoc analysis using LSD test. Spearman correlation

Table 2 Comparison between PCOS and control groups as regards all studied parameters

\begin{tabular}{|c|c|c|c|c|}
\hline & PCO group & Control group & \multirow{3}{*}{$\begin{array}{l}\text { Test } \\
\text { value }\end{array}$} & \multirow{3}{*}{$\begin{array}{l}P \\
\text { value }\end{array}$} \\
\hline & No. $=45$ & No. $=45$ & & \\
\hline & \multicolumn{2}{|l|}{ Mean \pm SD } & & \\
\hline Age (years) & $26.51 \pm 2.79$ & $27.78 \pm 3.90$ & $1.771 \cdot$ & 0.080 \\
\hline BMI $\left(\mathrm{kg} / \mathrm{m}^{2}\right)$ & $29.29 \pm 5.21$ & $28.93 \pm 5.11$ & -0.331 & 0.742 \\
\hline $\begin{array}{l}\text { Systolic blood } \\
\text { pressure }(\mathrm{mm} / \mathrm{Hg})\end{array}$ & $109.00 \pm 8.02$ & $108.67 \pm 7.10$ & -0.209 & 0.835 \\
\hline $\begin{array}{l}\text { Diastolic blood } \\
\text { pressure }(\mathrm{mm} / \mathrm{Hg})\end{array}$ & $69.00 \pm 7.04$ & $68.00 \pm 6.43$ & -0.704 & 0.484 \\
\hline Fasting blood sugar mg/dl & $84.89 \pm 4.96$ & $82.16 \pm 4.47$ & -2.746 & 0.007 \\
\hline Fasting insulin $\mu \mathrm{lU} / \mathrm{Ml}$ & $17.04 \pm 4.54$ & $10.67 \pm 2.77$ & -8.033 & 0.000 \\
\hline HOMA-IR & $3.59 \pm 1.05$ & $2.16 \pm 0.57$ & -7.999 & 0.000 \\
\hline Chemerin (ng/dl) & $94.99 \pm 12.52$ & $73.41 \pm 6.95$ & -10.103 & 0.000 \\
\hline
\end{tabular}


Table 3 Post hoc analysis (Obese PCO and lean control) as regards fasting insulin, HOMA-IR, and chemerin

\begin{tabular}{llll}
\hline \multicolumn{4}{l}{ Post hoc analysis by LSD } \\
\hline & Obese PCO & Lean control & $P$ value \\
\hline Fasting insulin $\mu \mathrm{IU} / \mathrm{L}$ & $19.50 \pm 4.21$ & $8.81 \pm 2.33$ & 0.000 \\
HOMA-IR & $4.12 \pm 1.03$ & $1.77 \pm 0.47$ & 0.000 \\
Chemerin $(\mathrm{ng} / \mathrm{dl})$ & $99.65 \pm 13.72$ & $69.16 \pm 8.40$ & 0.000 \\
\hline
\end{tabular}

coefficients were used to assess the correlation between two quantitative parameters in the same group.

\section{Results}

According to our case-control study, descriptive data of the four studied groups are shown in (Table 1). Chemerin level, fasting insulin and HOMA-IR were found to be significantly higher in $\mathrm{PCO}$ group than control group $(P<0.001)$, also fasting blood glucose was found to be higher in $\mathrm{PCO}$ group than control group $(P=0.007)$ (Table 2). In the post hoc analysis, chemerin level was found to be significantly higher in obese PCO group versus lean PCO, obese control, and lean control groups $(P$ $<0.001$ ) (Tables 3, 4, and 5), also chemerin level showed a statistically significant increase in lean PCO group versus obese control and lean control groups $(P<0.001)$ (Tables 6 and 7) and on correlating serum chemerin with different parameters in PCO group, we found a highly significant positive correlation between chemerin and BMI $(P<0.001)$, fasting insulin $(P<0.001)$, and HOMA-IR $(P<0.001)$ (Table 8$)$. Multivariate linear regression analysis for factors affecting the level of chemerin in both PCO groups showed that the most important factor affecting the level of chemerin in both PCO groups is fasting insulin $(P=0.042)$ (Table 9).

\section{Discussion}

Insulin resistance and other metabolic aberrations in PCOS women cannot be completely explained by abdominal adiposity but also altered adipokine secretion likely contribute to these abnormalities [6].

Chemerin, a recently discovered adipokine, seems to regulate adipocyte differentiation and control the expression of adipocyte genes that regulate glucose and lipid homeostasis [4].

Table 4 Post hoc analysis (obese PCO and obese control) as regards fasting insulin, HOMA-IR and chemerin

\begin{tabular}{llll}
\hline \multicolumn{4}{l}{ Post hoc analysis by LSD } \\
\hline & Obese PCO & Obese control & $P$ value \\
\hline Fasting insulin $\mu \mathrm{IU} / \mathrm{L}$ & $19.50 \pm 4.21$ & $12.15 \pm 2.16$ & 0.000 \\
HOMA-IR & $4.12 \pm 1.03$ & $2.47 \pm 0.44$ & 0.000 \\
Chemerin (ng/dl) & $99.65 \pm 13.72$ & $76.82 \pm 2.39$ & 0.000 \\
\hline
\end{tabular}

Table 5 Post hoc analysis (obese PCO and lean PCO) as regards fasting insulin, HOMA-IR, and chemerin

\begin{tabular}{llll}
\hline \multicolumn{4}{l}{ Post hoc analysis by LSD } \\
\hline & Obese PCO & Lean PCO & $P$ value \\
\hline Fasting insulin $\mu \mathrm{IU} / \mathrm{L}$ & $19.50 \pm 4.21$ & $13.34 \pm 1.45$ & 0.000 \\
HOMA-IR & $4.12 \pm 1.03$ & $2.79 \pm 0.37$ & 0.000 \\
Chemerin $(\mathrm{ng} / \mathrm{dl})$ & $99.65 \pm 13.72$ & $87.99 \pm 5.64$ & 0.000 \\
\hline
\end{tabular}

We conducted our study to assess chemerin level in PCO patients both lean and obese and to detect its relation to insulin resistance.

Our study confirmed higher level of chemerin in PCO group versus control group, also post hoc analysis showed that obese PCO group had the highest level of chemerin versus lean PCO, obese control, and lean control groups, also lean PCO group showed higher level of chemerin versus obese control and lean control groups. Also, chemerin showed high positive correlation with BMI.

This comes in line with Yang et al. who measured chemerin levels in PCOS women and healthy women and found that chemerin levels were significantly increased in patients with PCOS and they also found that there was a significant positive correlation between chemerin levels and BMI. Serum chemerin levels also significantly increased in obese and non-obese PCOS women, when compared with the corresponding obese and the nonobese control group; while chemerin levels in obese PCOS were significantly higher than non-obese PCOS women [7].

Also, Huang et al. measured chemerin in women with newly diagnosed PCOS using Rotterdam criteria and healthy individuals and showed that serum chemerin concentrations increase in PCOS patients, regardless of adiposity [8].

Guzel et al. and Ademoglu et al. found that serum levels of chemerin were significantly increased in PCOS women and a significant positive correlation was found between chemerin levels and BMI. Serum chemerin levels were significantly increased in obese and nonobese PCOS women, when compared with the corresponding obese and the non-obese control group; while chemerin levels in obese PCOS were significantly higher than non-obese PCOS women $[9,10]$.

Table 6 Post hoc analysis (lean PCO and obese control) as regards fasting insulin, HOMA-IR, and chemerin

Post hoc analysis by LSD

\begin{tabular}{llll}
\hline & Lean PCO & Obese control & $P$ value \\
\hline Fasting insulin $\mu \mathrm{IU} / \mathrm{L}$ & $13.34 \pm 1.45$ & $12.15 \pm 2.16$ & 0.185 \\
HOMA-IR & $2.79 \pm 0.37$ & $2.47 \pm 0.44$ & 0.124 \\
Chemerin $(\mathrm{ng} / \mathrm{dl})$ & $87.99 \pm 5.64$ & $76.82 \pm 2.39$ & 0.000 \\
\hline
\end{tabular}


Table 7 Post hoc analysis (lean PCO and lean control) as regards fasting insulin, HOMA-IR, and chemerin

\begin{tabular}{llll}
\hline \multicolumn{4}{l}{ Post hoc analysis by LSD } \\
\hline & Lean PCO & Lean control & $P$ value \\
\hline Fasting insulin $\mu \mathrm{IU} / \mathrm{L}$ & $13.34 \pm 1.45$ & $8.81 \pm 2.33$ & 0.000 \\
HOMA-IR & $2.79 \pm 0.37$ & $1.77 \pm 0.47$ & 0.000 \\
Chemerin $(\mathrm{ng} / \mathrm{dl})$ & $87.99 \pm 5.64$ & $69.16 \pm 8.40$ & 0.000 \\
\hline
\end{tabular}

In contrast to our results, Guvenc et al. measured chemerin level in women with PCOS and healthy women. The women were divided into subgroups of lean group (BMI 18.5-24.9 $\mathrm{kg} / \mathrm{m}^{2}$ ) and overweight group (BMI $25.0-29.9 \mathrm{~kg} / \mathrm{m}^{2}$ ) and showed that there was no difference in serum chemerin between PCOS patients and healthy controls. However, circulating chemerin was increased in overweight PCOS patients compared with lean PCOS patients and also they found that there was no significant difference between normal and overweight controls in serum chemerin. These findings suggest that BMI alone is not a predictive factor for circulating chemerin [11]. But this study did not include obese patients or patients with insulin resistance, which may explain the lack of any difference between groups.

Also in our study, PCO group has higher fasting blood glucose, fasting insulin, and HOMA IR than control group, being highest in obese PCO group, also chemerin positively correlated with fasting insulin, HOMA-IR, and fasting glucose which indicate that increased chemerin levels may involve in pathogenesis of metabolic aberrations in PCOS.

This comes in line with many studies Yang et al., Huang et al., Guzel et al., and Ademoglu et al. who documented significant increase of these parameters in obese and non-obese PCOS women, when compared with the corresponding obese and the non-obese control group [7-10].

Table 8 Correlation between chemerin level and the other studied parameters in PCO group

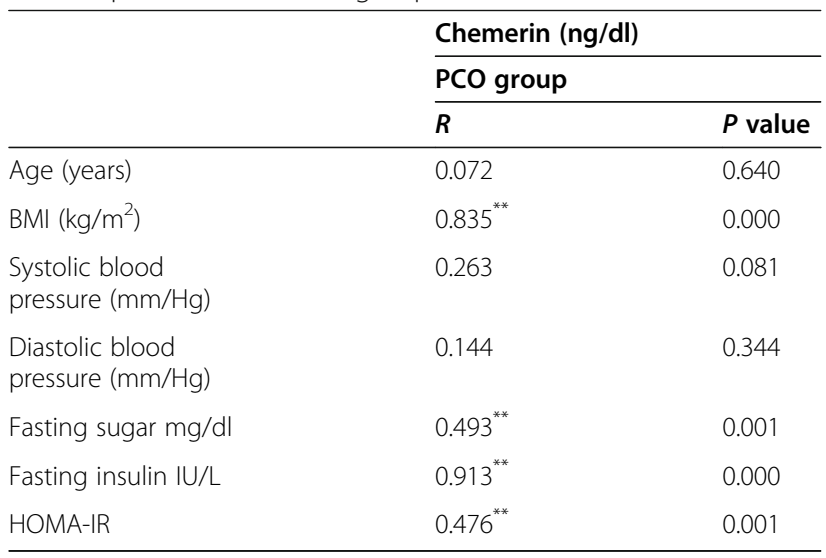

Table 9 Multivariate linear regression analysis for factors affecting the level of chemerin in both PCO groups

\begin{tabular}{|c|c|c|c|c|c|}
\hline & \multicolumn{2}{|c|}{ Unstandardizedcoefficients } & \multirow{2}{*}{$\begin{array}{l}\text { Standardized } \\
\text { coefficients } \\
\text { Beta }\end{array}$} & \multirow[t]{2}{*}{$t$} & \multirow[t]{2}{*}{ Sig. } \\
\hline & $B$ & Std. error & & & \\
\hline (Constant) & -18.772 & 52.763 & & $\overline{0}-356$ & 0.724 \\
\hline BMl & -0.495 & 0.274 & -0.206 & $\begin{array}{l}- \\
1.807\end{array}$ & 0.078 \\
\hline $\begin{array}{l}\text { Fasting } \\
\text { sugar mg/ } \\
\text { dl }\end{array}$ & 0.873 & 0.595 & 0.346 & 1.467 & 0.150 \\
\hline $\begin{array}{l}\text { Fasting } \\
\text { insulin IU/ } \\
L\end{array}$ & 6.026 & 2.868 & 2.183 & 2.101 & 0.042 \\
\hline HOMA-IR & -15.788 & 14.335 & -1.329 & $\begin{array}{l}- \\
1.101\end{array}$ & 0.278 \\
\hline
\end{tabular}

This agreeing with Kort et al. who postulated that chemerin may contribute to the pathogenesis of IR [12]. However, the exact regulation of chemerin on morbidity of IR and glucose metabolism is poorly understood, which may involve reduced glucose uptake and insulin sensitivity, chemerin receptors signaling pathways, or chronic inflammation [7].

\section{Conclusion}

Chemerin, a novel adipokine, was found to be higher in PCOS patients especially overweight ones and also correlated to the dysglycemic and insulin resistance indices which may indicate that chemerin has role in the pathogenesis of metabolic aberrations in PCOS like insulin resistance and diabetes.

\section{Abbreviations}

PCOS: Polycystic ovary syndrome; BMI: Body mass index; IR: Insulin resistance; HOMA-IR: Homeostatic Model Assessment for Insulin Resistance

\section{Acknowledgements}

To the technician who helped us in lab work, to the doctor helped us to do the study statistics.

\section{Authors' contributions}

$\mathrm{MH}$ chose the idea of the research, supervised all steps, and revised with us the manuscript. RA supervised all steps and revised with us the manuscript. YE revised statistical methods and final manuscript. MN revised final manuscript. LH wrote the whole manuscript. BT collected the data of the patients, performed statistical methods, and designed the tables. The manuscript has been read and approved by all the authors, and each author believes that the manuscript represents honest work.

Funding

No sources of funding

Availability of data and materials

All data generated or analyzed during this study are included in this published article.

Ethics approval and consent to participate

Our study was accepted by Ain Shams University Faculty of Medicine Research Ethics Committee (REC) FWA 000017858 and a written consent was taken from all subjects to be included in our study. 


\section{Consent for publication}

Not applicable

\section{Competing interests}

No competing interest.

Received: 15 July 2020 Accepted: 4 September 2020

Published online: 10 November 2020

\section{References}

1. Reaven GM (2011) Insulin resistance: the link between obesity and cardiovascular disease. Med Clin North Am:875-892

2. Toprak S, Onem AY, Cakir et al (2001) Insulin resistance in nonobese patients with polycystic ovary syndrome. Horm Res:65-70

3. Apridonidze T, Essah PA, luorno MJ, Nestler JE (2005) Prevalence and characteristics of the metabolic syndrome in women with polycystic ovary syndrome. J Clin Endocrinol Metab 4:1929-1935

4. Goralski KB, McCarthy TC, Hanniman EA, Zabel BA, Butcher EC, Parlee SD et al (2007) Chemerin, a novel adipokine that regulates adipogenesis and adipocyte metabolism. J Biol Chem 282:28175-28188

5. Rotterdam ESHRE/ASRM-Sponsored PCOS Consensus Workshop Group (2004) Revised 2003 consensus on diagnostic criteria and long-term health risks related to polycystic ovary syndrome. Fertil Steril 81:19-25

6. Dumesic DA, Oberfield SE, Stener-Victorin E, Marshall JC, Laven JS, Legro RS (2015) Scientific statement on the diagnostic criteria, epidemiology, pathophysiology, and molecular genetics of polycystic ovary syndrome. Endocr Rev 36:487-525

7. Yang S, Qiuyi W, Wei H, Yong S, Guimei F, Lu Z, Jing T (2015) Are serum chemerin levels different between obese and non-obese polycystic ovary syndrome women? Gynecol Endocrinol , Early Online: 1-4. Taylor \& Francis: 1075501. https://doi.org/10.3109/09513590

8. Huang A, Jiang Y, Yun S, Jun Z, Tao T, Shengxian L, Wei L (2015) Increased serum chemerin concentrations in patients with polycystic ovary syndrome. Clin Chim Acta 450:366-369

9. Guzel EC, Celik C, Abali R et al (2014) Omentin and chemerin and their association with obesity in women with polycystic ovary syndrome. Gynecol Endocrinol 30:419-422

10. Ademoglu E, Berberoglu Z, Carlioglu A (2014) Higher levels of circulating chemerin in both lean and obese patients with poly cystic ovary syndrome. Minerva Ginecol 66:535-542

11. Guvenc TT, Ahmet VA, Asli GO (2016) J Int Med Res:1-10

12. Kort DH, Kostolias A, Sullivan C, Lobo RA (2014) Chemerin as a marker of body fat and insulin resistance in women with polycystic ovary syndrome. Gynecol Endocrinol 8:1-4

\section{Publisher's Note}

Springer Nature remains neutral with regard to jurisdictional claims in published maps and institutional affiliations.

\section{Submit your manuscript to a SpringerOpen ${ }^{\circ}$ journal and benefit from:}

- Convenient online submission

- Rigorous peer review

- Open access: articles freely available online

- High visibility within the field

- Retaining the copyright to your article 